https://helda.helsinki.fi

Biochemical and immunohistochemical identification of MMP-7 in human dentin

\title{
Mazzoni, Annalisa
}

2018-12

Mazzoni , A, Maravic , T , Tezvergil-Mutluay , A , Tjäderhane , L , Scaffa , P M C , Seseogullari-Dirihan , R , Bavelloni , A , Gobbi , P , Pashley , D H , Tay , F R \& Breschi , L 2018 , 'Biochemical and immunohistochemical identification of MMP-7 in human dentin ' , Journal of Dentistry , vol. 79 , pp. 90-95 . https://doi.org/10.1016/j.jdent.2018.10.008

http://hdl.handle.net/10138/307702

https://doi.org/10.1016/j.jdent.2018.10.008

publishedVersion

Downloaded from Helda, University of Helsinki institutional repository.

This is an electronic reprint of the original article.

This reprint may differ from the original in pagination and typographic detail.

Please cite the original version. 


\title{
Biochemical and immunohistochemical identification of MMP-7 in human dentin
}

\author{
Annalisa Mazzoni ${ }^{\mathrm{a}}$, Tatjana Maravića ${ }^{\mathrm{a}}$ Arzu Tezvergil-Mutluay ${ }^{\mathrm{b}, \mathrm{c}}$, Leo Tjäderhane ${ }^{\mathrm{d}, \mathrm{e}}$, \\ Polliana Mendes Candia Scaffa ${ }^{\mathrm{f}}$, Roda Seseogullari-Dirihan ${ }^{\mathrm{b}, \mathrm{c}}$, Alberto Bavelloni ${ }^{\mathrm{g}}$, Pietro Gobbi ${ }^{\mathrm{h}}$, \\ David H. Pashley ${ }^{\mathrm{i}}$, Franklin R. Tay ${ }^{\mathrm{i}}$, Lorenzo Breschi ${ }^{\mathrm{a}, *}$ \\ a Department of Biomedical and Neuromotor Sciences, DIBINEM, University of Bologna-Alma Mater Studiorum, Via San Vitale 59, Bologna, Italy \\ ${ }^{\mathrm{b}}$ Department of Restorative Dentistry and Cariology, Adhesive Dentistry Research Group Institute of Dentistry, University of Turku, FI-20014 Turun Yliopisto, Turku \\ Finland \\ ${ }^{\mathrm{c}}$ Turku University Hospital, Kïnamyllynkatu 4-8 Turku, Finland \\ ${ }^{\mathrm{d}}$ Department of Oral and Maxillofacial Diseases, University of Helsinki, Helsinki University Hospital, Mannerheimintie 172, o0014 Helsinki, Finland \\ ${ }^{\mathrm{e}}$ Research Unit of Oral Health Sciences, Medical Research Center Oulu (MRC Oulu), Oulu University Hospital and University of Oulu, Pentti Kaiteran katu 1, Linnanmaa, \\ Oulu, Finland \\ ${ }^{\mathrm{f}}$ Faculty of Dentistry at Piracicaba, University of Campinas, Av. Limeira, 901 - Areião, Piracicaba, Brazil \\ ${ }^{\mathrm{g}}$ Laboratory of Musculoskeletal Cell Biology, Rizzoli Orthopedic Institute, Via di Barbiano, 1/10, 40136 Bologna, Italy \\ ${ }^{\mathrm{h}}$ Department of Biomolecular Sciences, University of Urbino Carlo Bo, Via Aurelio Saffi 2, Urbino, Italy \\ ${ }^{\mathrm{i}}$ The Dental College of Georgia, Augusta University, 1430 John Wesley Gilbert Drive, Augusta, Georgia, USA
}

\section{A R T I C L E I N F O}

\section{Keywords:}

MMPs

Dentine

Collagen

Extra-cellular matrix

Immunohistochemistry

Biochemistry

\begin{abstract}
A B S T R A C T
Objectives: Matrix metalloproteinases (MMPs) are dentinal endogenous enzymes claimed to have a vital role in dentin organic matrix breakdown. The aim of the study was to investigate presence, localization and distribution of MMP-7 in sound human dentin.

Methods: Dentin was powdered, demineralized and dissolved in isoelectric focusing buffer. Resolved proteins were transferred to nitrocellulose membranes for western blotting (WB) analyses. For the zymographic analysis, aliquots of dentin protein were electrophoresed in $12 \%$ sodium dodecyl sulfate-polyacrylamide gel electrophoresis containing fluorescently labeled gelatin. Further, the concentrations of dentinal MMPs were measured using Fluorescent Microsphere Immunoassay with a human MMP-MAP multiplex kit. Pre- and post-embedding immunolabeling technique was used to investigate the localization and distribution of MMP-7 in dentin. Dentin was cryo-fractured, the fragments partially decalcified and labeled with a primary monoclonal anti-MMP-7 and a secondary antibody conjugated with gold nanoparticles. MMP-7 labelings were identified in the demineralized dentin matrix as highly electron-dense dispersed gold particles.

Results: WB and zymographic analysis of extracted dentin proteins showed presence of MMP-7 ( 20-28 KDa). Further, MMP-7 was found in the supernatants of the incubated dentin beams using Fluorescent Microsphere Immunoassay. FEI-SEM and TEM analyses established MMP-7 as an intrinsic constituent of the human dentin organic matrix.

Conclusion: This study demonstrated that MMP-7 is an endogenous component of the human dentin fibrillar network.

Clinical significance: It is pivotal to understand the underlying processes behind dentin matrix remodeling and degradation in order to develop the most optimal clinical protocols and ensure the longevity of dental restorations.
\end{abstract}

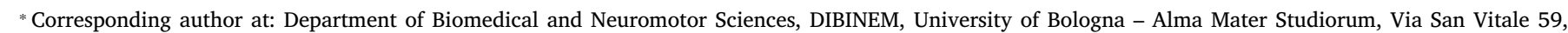
40125, Bologna, Italy.

E-mail addresses: annalisa.mazzoni@unibo.it (A. Mazzoni), tatjana.maravic@studio.unibo.it (T. Maravić), arztez@utu.fi (A. Tezvergil-Mutluay),

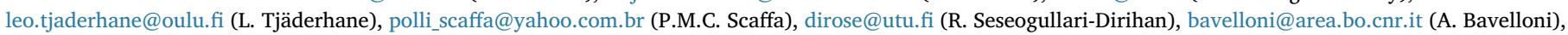
pietro.gobbi@uniurb.it (P. Gobbi), dpashley@gru.edu (D.H. Pashley), ftay@augusta.edu (F.R. Tay), lorenzo.breschi@unibo.it (L. Breschi). 


\section{Introduction}

Matrix metalloproteinases (MMPs) are a family of zinc-dependent proteolytic enzymes involved in the degradation of extracellular matrix components (ECM) in various tissues, including dentin. This degradative activity is essential for normal physiologic processes. However, increase or uncontrolled activity may occur in pathologic conditions [1]. Currently, 23 MMPs possessing various catalytic properties have been identified. Based on homology and substrate specificity, they are classified into six groups: collagenases, gelatinases, stromelysins, matrilysins, membrane-type MMPs (MT-MMPs) and other MMPs [2].

Although human odontoblasts express a wide spectrum of at least 17 MMPs [3], not all of MMPs have been identified in dentin. These dentin MMPs include the gelatinases MMP-2 and MMP-9 [4,5], collagenase MMP-8 [6,7], stromelysin MMP-3 [8] and enamelysin MMP$20[6,7]$. These MMPs are believed to participate in practically all dental hard tissue pathologies, including dentinal caries $[9,10]$, degradation of the resin-dentin interface of resin composite restorations [11] and dentin erosion [12]. In particular, MMP-2 and MMP-9 are important in caries progression $[13,14]$ and degradation of the resindentin interface [10,15-17].

Matrilysin-1, also known as MMP-7, possesses proteolytic activity against a wide range of ECM components, many of which also exist in dentin. This protease interacts with proteoglycans and their glycosaminoglycan chains, resulting in catalysis of specific substrates [18]. Matrix metalloproteinase-7 has the ability to activate several other latent collagenolytic MMPs, including MMP-2 and MMP-9 [19-21]. While the expression and activity of MMP-2 and MMP-9 in dentin have already been reported, information on the presence and activity of MMP7 in dentin tissues is lacking. Accordingly, the objective of the present study was to assess the distribution of MMP-7 in sound human dentin using correlative zymographic, biochemical and immunohistochemical techniques.

\section{Materials \& methods}

\subsection{Preparation of mineralized dentin powder}

Six extracted human third molars were obtained from anonymous subjects following their signed consent under a protocol approved by the University of Trieste, Italy. After the extracted teeth were ground free of enamel, pulpal soft tissue and cementum, they were reduced to a fine powder by freezing the dentin fragments in liquid nitrogen and triturating them using a steel mortar/pestle (Reimiller, Reggio Emilia, Italy). The dentin powder of the six teeth was mixed, dried and kept frozen until use.

\subsection{Demineralization procedures}

The dentin powder was demineralized with $10 \%$ phosphoric acid for 10 min under constant agitation. After adding $5 \mathrm{~N} \mathrm{NaOH}$ to buffer the phosphoric acid, the mixture was agitated and centrifuged for $20 \mathrm{~min}$ $(20,800 \mathrm{~g})$ at $4{ }^{\circ} \mathrm{C}$, re-suspended in distilled water and re-centrifuged $\left(20 \mathrm{~min} 20,800 \mathrm{~g}\right.$ at $4^{\circ} \mathrm{C}$ ). The water was discarded and the precipitate was left to air-dry at ambient temperature.

\subsection{Protein fractionation by isoelectric focusing}

In isoelectric focusing, proteins are separated based on their isoelectric points using electrophoresis. The demineralized dentin powder was suspended overnight at $4{ }^{\circ} \mathrm{C}$ in $2.5 \mathrm{~mL}$ of isoelectric focusing buffer, consisting of $7 \mathrm{M}$ urea, $2 \mathrm{M}$ thiourea, $5 \mathrm{mM}$ dithiothreitol (DTT), $4 \%$ $(\mathrm{w} / \mathrm{v})$ Chaps and $2 \%(\mathrm{v} / \mathrm{v})$ Pharmalyte, $\mathrm{pH} 3-10$; Thermo Fisher Scientific, Waltham, MA) to extract proteins. The extracted proteins were recovered by centrifugation $(21,000 \mathrm{~g}$ for $30 \mathrm{~min}$ at room temperature). The supernatant was loaded into the MicroRotofor (BioRad Laboratories, Hercules, CA), and electrophoresis was performed for $3 \mathrm{~h}$ at $1 \mathrm{~W}$ and $20^{\circ} \mathrm{C}$, according to the manufacturer's instructions. The recovered proteins were subsequently dissolved in $30 \mu \mathrm{L}$ of sodium dodecyl sulfate buffer, boiled for $5 \mathrm{~min}$ and subjected to mono-dimensional electrophoresis. Resolved proteins were transferred to nitrocellulose membranes (Bio-Rad) for Western blot.

\subsection{Western blot for MMP-7}

Membranes were stained with Ponceau red (MilliporeSigma, St. Lois, MA) and cut in order to separate the molecular weights corresponding to MMP-7. The membranes were blocked for 90 min with $5 \%$ bovine serum albumin solubilized in Tris-buffered saline containing $0.1 \%$ Tween-20 (pH 7.5; TBS-T) and incubated overnight at $4{ }^{\circ} \mathrm{C}$ with a primary anti-MMP-7 antibody (Calbiochem, San Diego, CA) diluted 1:200 in TBS-T. The membranes were subsequently washed 3 times for a total of $15 \mathrm{~min}$ in TBS-T and incubated with a secondary antibody (horseradish peroxidase-conjugated anti-mouse IgG, MilliporeSigma) diluted 1:50,000 in TBS-T. After incubation with the secondary antibody, the membranes were washed in TBS-T 3 times for $15 \mathrm{~min}$ and incubated with enhanced chemiluminescence detection reagents (GE Healthcare, Chicago, IL). Images were acquired with Kodak image station 2000R (Kodak, Rochester, NY).

\subsection{Zymography}

The demineralized powder was suspended in $1 \mathrm{~mL}$ of extraction buffer (50 mM Tris-HCl, pH 6, containing $5 \mathrm{mM} \mathrm{CaCl}_{2}, 100 \mathrm{mM} \mathrm{NaCl}$, $0.1 \%$ Triton $\mathrm{X}-100$ ) for $24 \mathrm{~h}$ at $4{ }^{\circ} \mathrm{C}$ under constant agitation. The samples were then subjected to sonication for $10 \mathrm{~min}$ in cold water (at $\approx 30$ pulses) and consecutively centrifuged for $20 \mathrm{~min}$ at $4{ }^{\circ} \mathrm{C}(20,800 \mathrm{~g})$. The supernatant was collected and recentrifuged $\left(20 \mathrm{~min}\right.$ at $4^{\circ} \mathrm{C}$, $20,800 \mathrm{~g}$ ) as to remove any remnants of the powder. After centrifuging, proteins in the supernatant were precipitated using VIVASPIN $10,000 \mathrm{Da}$ centrifugal concentrators (Millipore) at $25^{\circ} \mathrm{C}, 3$ times for $30 \mathrm{~min}$ at $25^{\circ} \mathrm{C}(15,000 \mathrm{~g})$.

The total protein concentration of the extracts was determined using the Bradford assay. Laemmli sample buffer was used to dilute dentin protein aliquots in a 4:1 ratio. Electrophoresis was performed under non-reducing conditions using $12 \%$ sodium dodecyl sulfate-polyacrylamide gel electrophoresis (SDS-PAGE) containing $1 \mathrm{mg} / \mathrm{mL} \mathrm{2-}$ methoxy-2,4-diphenyl-3(2 H)-furanone-labeled fluorescent gelatin [22]. SDS-PAGE pre-stained low-range molecular weight standard (BioRad) was used as molecular-weight marker. After electrophoresis, the gels were washed for $1 \mathrm{~h}$ in $2 \%$ Triton X-100 and incubated in the activation solution ( $50 \mathrm{mmol} / \mathrm{L}$ Tris-HCl, $5 \mathrm{mmol} / \mathrm{L} \mathrm{CaCl} 2, \mathrm{pH} 7.4$ ) for $48 \mathrm{~h}$. The gels were photographed under UV illumination (Gel Doc XR System, Bio-Rad). For inhibition of proteolytic activities, one gel was incubated in the aforementioned buffer in the presence of $2 \mathrm{mM} \mathrm{1,10-}$ phenanthroline (MillioporeSigma), an MMP inhibitor, and another gel was incubated in the presence of $10 \mu \mathrm{M} \mathrm{E}-64$ (MilliporeSigma), a cysteine protease inhibitor.

\subsection{Multiplexed fluorescent bead-based immunoassay}

Ten additional extracted human third molars were used for this part of the experiment. The enamel and superficial dentin of each tooth were removed using an Isomet saw (Buehler Ltd., Lake Bluff, IL) under water cooling. Ten mid-coronal dentin beams $(6 \times 2 \times 1 \mathrm{~mm})$ were sectioned. The beams were completely demineralized in $10 \%$ phosphoric acid for $24 \mathrm{~h}$ at $4{ }^{\circ} \mathrm{C}$. Each beam was further incubated with $1 \mathrm{~mL}$ of extraction buffer $\left(50 \mathrm{mM}\right.$ Tris- $\mathrm{HCl} \mathrm{pH} 6$, containing $5 \mathrm{mM} \mathrm{CaCl}_{2}$, $100 \mathrm{mM} \mathrm{NaCl}, 0.1 \%$ Triton X-100, $0.1 \mathrm{mM} \mathrm{ZnCl}_{2}$ ) for $24 \mathrm{~h}$. The specimens were subsequently centrifuged, and supernatants were collected.

The concentrations of dentinal MMP-2, MMP-3 and MMP-7 were 
measured using Fluorescent Microsphere Immunoassay with a human MMP-MAP multiplex kit (R\&D Systems, Inc., Minneapolis, MN). Following the manufacturer's instructions, reagents and the supernatants from each beam were pipetted into wells in duplicate and incubated for $2 \mathrm{~h}$ at room temperature with specific pre-coated antibodies on color-coded magnetic microparticles. Unbound biotinylated antibody were then washed and streptavidin-phycoerythrin conjugate (streptavidin-PE) was added to each well and incubated for $30 \mathrm{~min}$ at room temperature. After a final wash to remove unbound streptavidin-PE, the microparticles were re-suspended in buffer and measured using a Luminex1 200TM Analyzer (Luminex Systems, Northbrook, IL) and associated software. The robust mean and the median fluorescence intensity from 100 microspheres of each set were calculated. After fitting of the standard curves (5 parameters fitting program), concentrations were calculated using the MILLIPLEX Analyst software (Merck Millipore, Burlington, MA). Data were analyzed with one-way ANOVA and post-hoc Tukey multiple comparison procedures after confirming the normality and homoscedasticity assumptions of the data sets. Statistical significance was ore-set at $\alpha=0.05$.

\subsection{Immunohistochemical identification of $M M P-7$}

An additional five human sound third molars were cryo-fractured after immersion in liquid nitrogen to produce smear layer free dentin specimens. Five major fragments were selected from each tooth under stereomicroscope (Zeiss Stemi 2000-C, Carl Zeiss Jena GmbH, Jena, Germany) and randomly assigned to a pre-embedding or a post-embedding labeling technique in accordance with a previously-reported technique $[4,8]$

\subsubsection{Pre-embedding field emission in-lens scanning electron microscopy (FEI-SEM)}

The specimens were partially decalcified in $0.5 \mathrm{M}$ ethylene diamine tetraacetic acid (EDTA; $\mathrm{pH} 7.4$ ) for $30 \mathrm{~min}$ at $25^{\circ} \mathrm{C}$, rinsed with distilled water, immersed in $0.05 \mathrm{M}$ Tris $\mathrm{HCl}$ buffer solution (pH 7.6) 3 times for $3 \mathrm{~min}$, pre-incubated in normal goat serum (British BioCell International, Cardiff, United Kingdom) in $0.05 \mathrm{M}$ TBS (pH 7.6) at room temperature for $30 \mathrm{~min}$, and incubated overnight with anti-MMP-7 primary antibody (Calbiochem; dilution 1:100 in 0.05 M TBS, pH 7.6) at $4{ }^{\circ} \mathrm{C}$. After extensive rinsing in $0.05 \mathrm{M}$ TBS (pH 7.6) and $0.02 \mathrm{M}$ TBS (pH 8.2) (both 3 times for $3 \mathrm{~min}$ ), gold labeling was performed using secondary antibodies. The latter comprised goat anti-mouse IgG conjugated with $15 \mathrm{~nm}$ colloidal gold nanoparticles (British BioCell International; dilution $1: 20$ ) in $0.02 \mathrm{M} \mathrm{TBS}(\mathrm{pH} 8.2$ ) at room temperature for $90 \mathrm{~min}$. After immunostaining, the specimens were rinsed in $0.02 \mathrm{M}$ TBS (pH 8.2) 3 times for 3 min, fixed with $2.5 \%$ glutaraldehyde in $0.15 \mathrm{M}$ cacodylate buffer ( $\mathrm{pH} 7.2$ ) for $4 \mathrm{~h}$, rinsed in $0.15 \mathrm{M}$ cacodylate buffer, dehydrated in ascending ethanol series $(50 \%, 70 \%, 90 \%$, $95 \%, 100 \%$ ), and dried by gradually adding drops of hexamethyldisilasane into the $100 \%$ ethanol, followed by full immersion of the specimen in hexamethyldisilasane [23]. The chemically-desiccated specimens were mounted on aluminum stubs, carbon coated and examined using FEI-SEM (JSM 890, JEOL Ltd., Tokyo, Japan) at $7 \mathrm{Kv}$ and $1 \times 10^{-12}$ Amp. Images were obtained, using a combination of backscattered and secondary electron from areas considered as representative for each specimen.

\subsubsection{Post-embedding transmission electron microscopy (TEM)}

Dentin fragments assigned to the post-embedding technique were decalcified using 4.13\% EDTA for 3 months followed by washing with $0.1 \mathrm{M}$ cacodylate buffer ( $\mathrm{pH}$ 7.2). The decalcified specimens were dehydrated in ascending ethanol series $(30 \%, 50 \%, 70 \%, 80 \%, 90 \%$, $100 \%$ ) and embedded in LR White resin (London Resin, Berkshire, UK). Eighty-nanometer-thick sections were cut with an ultramicrotome (Reichert Jung Ultracut, C. Reichert AG, Vienna, Austria) and mounted on formvar carbon-coated nickel grids. The mounted tissue sections were immunohistochemically labeled in accordance with the post-embedding technique reported by Mazzoni et al. [4]. Firstly, as to remove the superficial layer of resin and uncover the collagen, the specimens were etched with meta periodate in saturated solution for $30 \mathrm{~min}$, washed in distilled water ( 3 times for $3 \mathrm{~min}$ ), then treated with $0.1 \mathrm{M}$ $\mathrm{HCl}$ for $10 \mathrm{~min}$ and washed in distilled water ( 3 times for $3 \mathrm{~min}$ ). Immunolabeling was performed in the same manner as described for the pre-embedding technique using the same primary antibody for MMP-7, followed by the colloidal gold-conjugated secondary antibody. Grids were stained with $4 \%$ uranyl acetate $(15 \mathrm{~min})$ and Reynold's lead citrate $(15 \mathrm{~min})$ for examination with a JEOL 1010 TEM at $60 \mathrm{kV}$.

\subsubsection{Controls}

Controls were processed in accordance with a previously-reported technique $[4,8]$. The dentin specimens were first incubated only in $0.05 \mathrm{M}$ TBS ( $\mathrm{pH} 7.6$ ) without the primary antibodies overnight, and subsequently with the secondary antibody. This was followed by immersion of the specimens in a proteolytic agent (5\% sodium hypochlorite) for $30 \mathrm{~min}$, which was followed by extensive rinsing with distilled water. The proteolytic agent was applied on the partially-demineralized dentin surface prior to the immunohistochemical staining to remove the organic matrix for demonstrating the absence of primary and secondary antibodies.

\section{Results}

\subsection{Western blotting for MMP-7}

Western-blot revealed intense expression of MMP-7, as demonstrated by a strong band at approximately $25 \mathrm{kDa}$. This band corresponded with the MMP-7 pro-form (Fig. 1a). Expression of MMP-7 was different at different $\mathrm{pH}$ values; $\mathrm{pH}$ values from 6 to 9 were found to be optimal for the extraction of MMP-7 (Fig. 1a).

\subsection{Zymography}

Gelatinolytic activities expressed by the investigated groups are shown in Fig. 1b. Mineralized dentin powder and the gel incubated in the buffer in the presence of E-64 showed enzymatic activity corresponding to the molecular weight of pro-form and active forms of MMP-
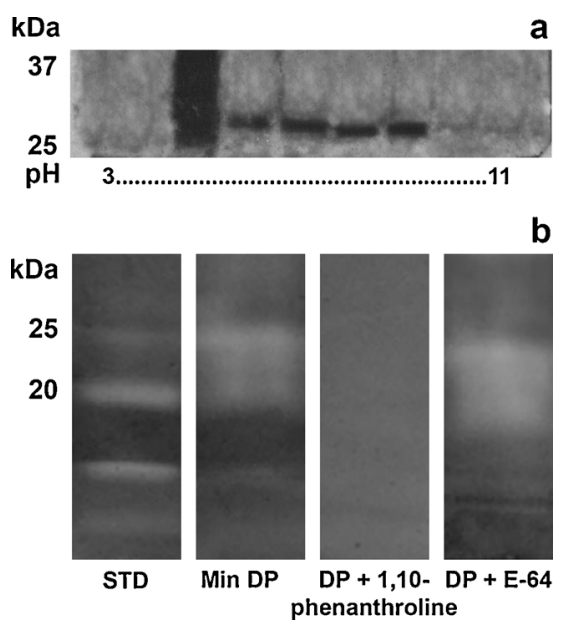

Fig. 1. (a) Western blot analysis. Immunoreactivity against monoclonal antihuman MMP-7 detected as a strong band at approximately $25 \mathrm{kDa}$ corresponding to MMP-7 pro-form at $\mathrm{pH} 3-\mathrm{pH} \mathrm{11;} \mathrm{(b)} \mathrm{Dentin} \mathrm{extract} \mathrm{analyzed} \mathrm{by}$ gelatin zymography. The molecular masses are expressed in $\mathrm{kDa}$ and reported in STD lane. Gelatinolytic activity detected at $20-25-\mathrm{kDa}$, corresponding to the molecular weight of proMMP-7. No gelatinolytic activity was observed after incubation in $2 \mathrm{mM}$ 1,10-phenanthroline, however, the activity was present when the gel was incubated with cysteine protease inhibitor $(10 \mu \mathrm{M} \mathrm{E}-64)$. 


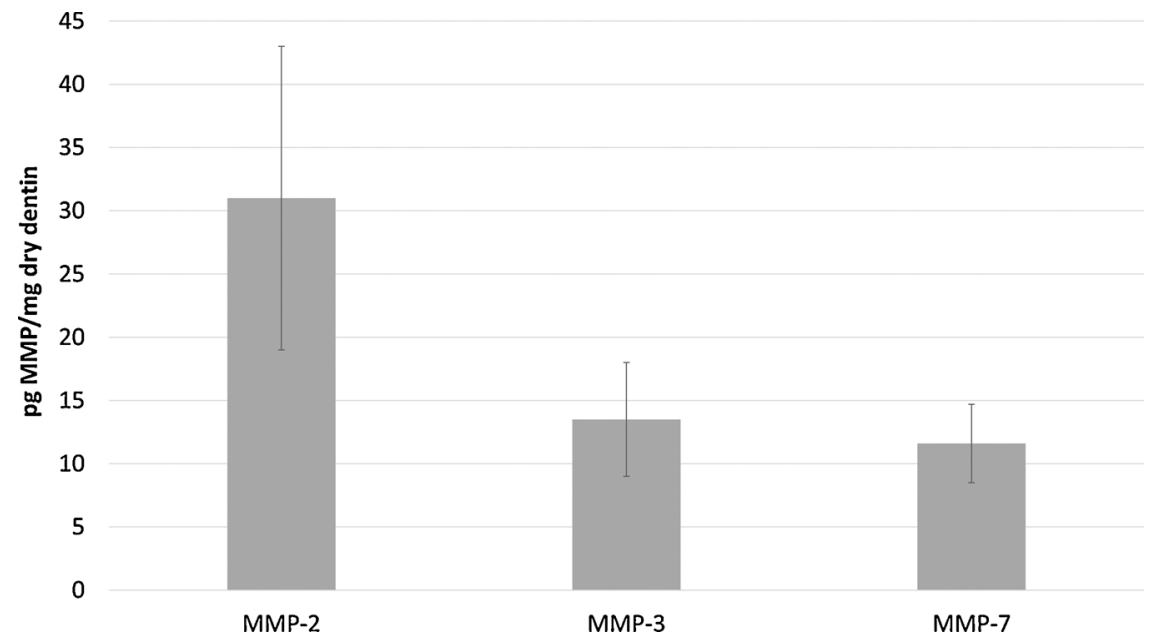

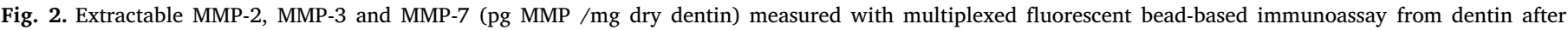
demineralization in $10 \%$ phosphoric acid. Extractable MMP-2 was significantly higher than MMP-3 and MMP-7 (p < 0.05 ).

7. The gel incubated with 1,10-phenanthroline showed no enzymatic activity. The specificity of the zymographic assay was verified because gelatinolytic activity was inhibited only by the MMP inhibitor and not by the cysteine protease inhibitor.

\subsection{Multiplexed fluorescent bead-based immunoassay}

The amount of extractable MMP-2, -3 and -7 is presented in Fig. 2. The amount of MMP-2 was significantly higher than that of MMP-3 or MMP-7 ( $\mathrm{p}<0.05$ ). There was no significant difference between the levels of extracted MMP-3 and MMP-7.

\subsection{Immunohistochemical identification of MMP-7}

Positive immunolabeling for MMP-7 was identified using FEI-SEM from partially-decalcified dentin surfaces. Gold nanoparticles appeared as spherical white marks of approximately $15 \mathrm{~nm}$ in diameter (Fig. 3). The MMP-7 was predominantly localized along the collagen fibrillar network and appeared to be anchored to the collagen fibrils (Fig. 3a-c). Examination of post-embedded specimens with TEM revealed immunoreactivity for MMP-7, with the gold nanoparticles appearing as black spherical spots of approximately $15 \mathrm{~nm}$ in diameter (Fig. 3d-f). The immunoreaction appeared to be randomly distributed across the intertubular dentin. For both FEI-SEM and TEM examination, a similar distribution for MMP-7 was identified from the coronal and radicular dentin. No immunohistochemical staining was observed from the control specimens, which was indicative of the absence of cross-reactions between the secondary antibodies and the dentin organic matrix (control \#1), or between the secondary antibodies and the inorganic phase (control \#2) (data not shown).

\section{Discussion}

The present study was the first to reveal the presence and distribution of MMP-7 in human dentin using immunohistochemical and biochemical assays. Matrilysin-1, also known as MMP-7, is the smallest member of the MMP family because it lacks the C-terminal hemopexin domain common to other MMPs. It has a molecular weight of $28 \mathrm{kDa}$, which can be activated into active species of 21 and $19 \mathrm{kDa}$ by proteolytic removal of the pro-domain from the $\mathrm{N}$ terminus [24]. This metalloproteinase possesses a broad substrate spectrum and displays strong proteolytic activity against a wide range of ECM components, some of which also exist in dentin. These include proteoglycans, fibronectin, gelatin, laminin, elastin, tenascin-C, ostenectin, osteopontin, fetuin and type IV collagen [25-31].
To better understand the specific role of MMP-7 in mature human dentin, it is important to clarify its distribution and function in relation to other dentinal MMPs, which might be structurally and/or functionally associated. In the present study, the amounts of extractable MMP-7 and MMP-3 were about two-fold lower than the amount of MMP-2; the latter has been reported as the most abundant MMP in dentin [32]. Having previously identified the presence and distribution of MMP-3 in human dentin using immunohistochemical and biochemical assays [8], the authors have observed similarities between MMP-7 and MMP-3. Both MMPs showed a similar distribution in dentin and appeared to be attached to the collagen fibrils within the collagen fibrillar network. Interestingly, MMP-7 and MMP-3 share a number of substrates, some of which may have implications in peritubular dentin mineralization, such as fetuin-A [31,33-35]. Recently, Schure et al. [31] demonstrated that both MMP-7 and MMP-3 can degrade fetuin, although MMP-7 is about three-fold more effective. Since fetuin is one of the best serum inhibitors of ectopic calcification and the most abundant serum protein in dentin [34], MMP-7 and -3 can work in concert to reduce the inhibition of mineralization by fetuin. Fetuin is also a regulator of MMP-2 and MMP9 activities, because it can change the pro-form of these enzymes into the active form. Such a process prevents autolysis of those MMPs and protects their activities $[32,33,35,36]$. Accordingly, one may hypothesize that the degradation/activation interplay of MMP-7 and MMP-3 with fetuin and MMP-2 and MMP-9 plays a physiological role in peritubular dentin mineralization. This hypothesis has to be tested in future studies.

Apart from the ability of MMP-7 to degrade various non-collagenous ECM components, MMP-7 also has the ability to activate several other latent collagenolytic MMPs, including MMP-2, MMP-9 and MMP-8 [19-21]. Thus, two mechanisms may be responsible for the involvement of MMP-7 in physiological and pathological conditions: the direct effects of MMP-7 proteinase activity and the indirect effects of MMP-7 related to the activation of MMP-2, MMP-9 and MMP-8. The latter is particularly important since activated MMP-2 and MMP-9 are type I collagen telopeptidases $[10,37,38]$ that enable the access of true collagenases to the catalytic site on the collagen triple helix. With the involvement of true collagenases, the tropocollagen helix can further unwind on specific sites, resulting in cleaving of the trocollagen molecules [39]. Hence, the activity of MMP-2 and MMP-9 may also be regulated by the level of MMP-7 activity and the inhibition of MMP-7 may provide a more effective inhibition of dentinal gelatinase activities.

A real-time PCR study showed that MMP-7 is expressed only by odontoblasts and is absent from pulp tissues; however, the role of MMP7 in mature odontoblasts is still unknown [3]. In the present study, the presence of pro-MMP-7 has been shown in dentin extracts for the first 
FEI-SEM

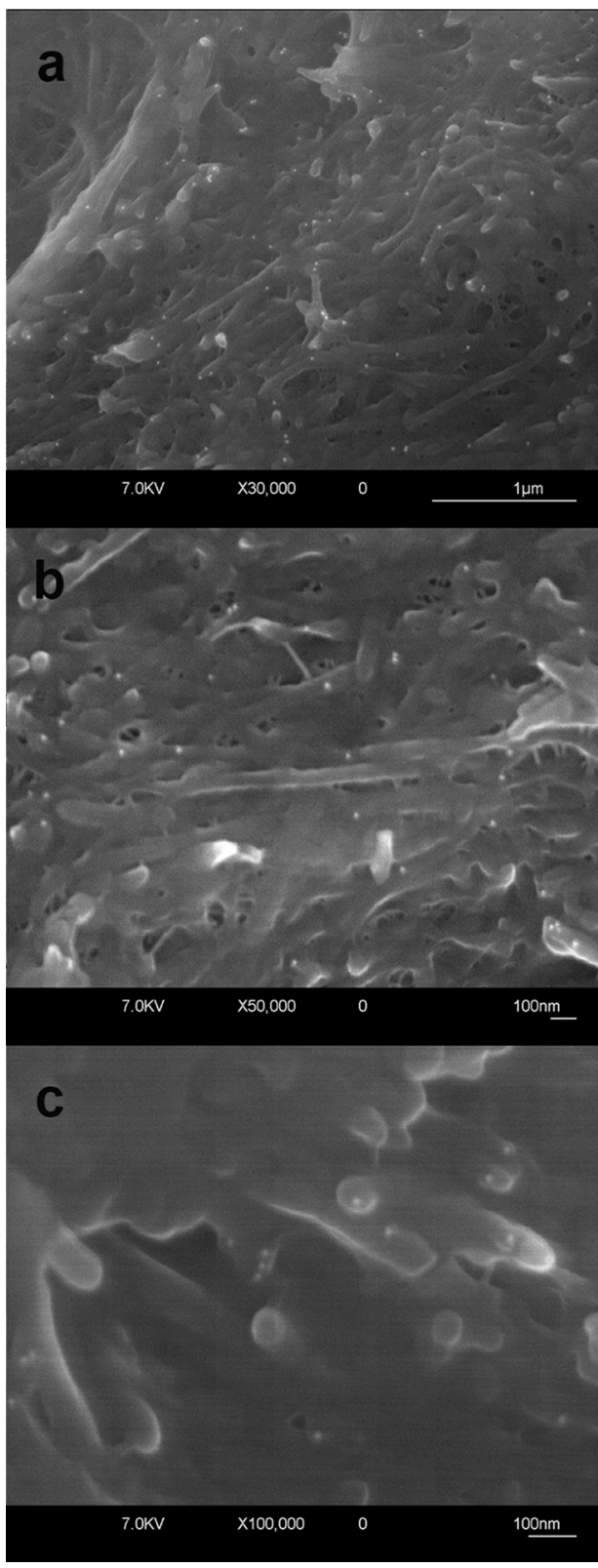

TEM

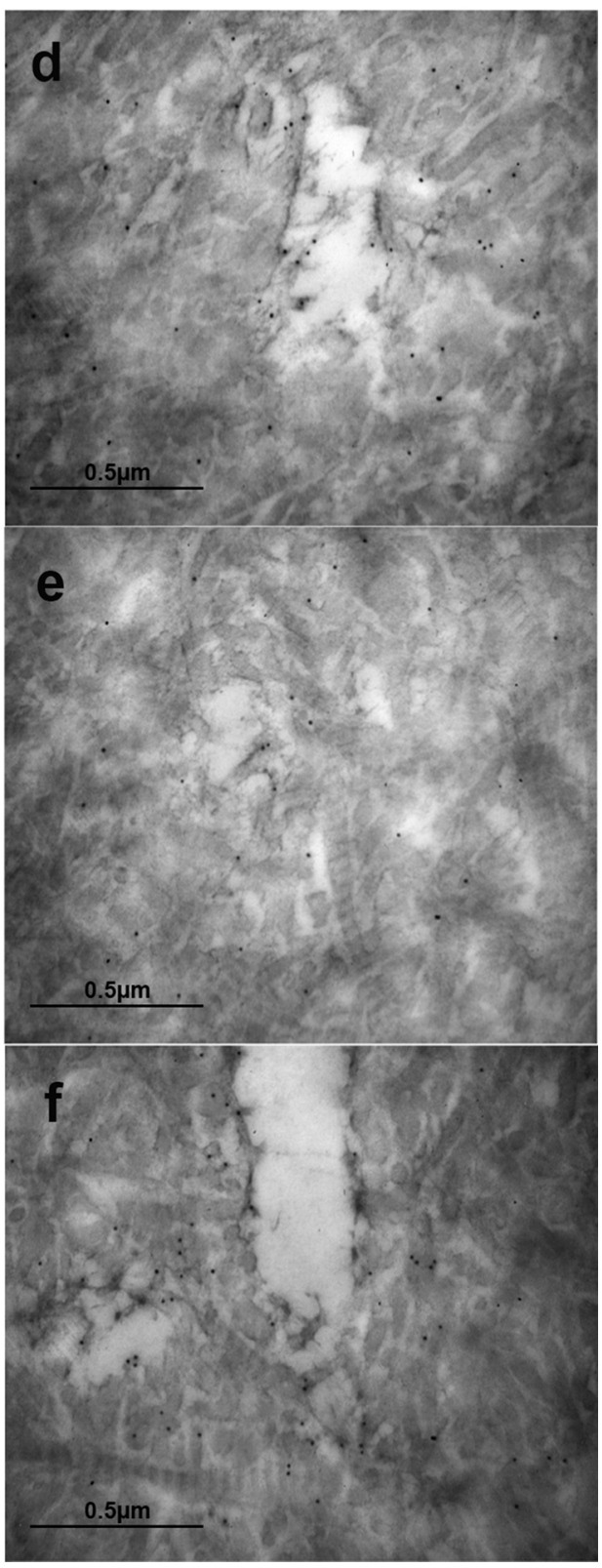

Fig. 3. Field emission in-lens SEM (FEI-SEM) micrographs of unfixed, partially demineralized dentin after a pre-embedding immunolabelling procedure with monoclonal antibody for MMP-7. All images were obtained by a combination of secondary electron and backscattered electron signals to simultaneously reveal immunogold labelling and related substrate morphology. Labelling can be identified as electron-dense white spots. (a) Low magnification $(\times 30,000)$ of the partially demineralized dentin surface showing the distribution of MMP-7. (b) Higher magnification $(\times 50,000)$ of the dentin substrate showing positive immunohistochemical staining identifying MMP-7 antibody located along the collagen fibrils; (c) High magnification FEI-SEM micrographs $(\times 100,000)$, revealing MMP-7 distribution within the dentin substrate $(\mathrm{d}, \mathrm{e}, \mathrm{f})$ TEM micrographs of unfixed demineralized dentin after a postembedding immunolabeling procedure with monoclonal antibodies for MMP-7. Labeling can be identified as black spots under the electron beam showing positive immunoreaction for MMP-7 (d,e,f; bar $0.1 \mu \mathrm{m})$. time; the zymogen pro-MMP-7 (approximately 20-25 kDa) was enzymatically and immunologically detected (Figs. 1 and 2). The specific $\mathrm{Ca}$ and $\mathrm{Zn}$ requirements for the proteolytic activity of MMP-7, as demonstrated by 1,10-phenanthroline inhibition, confirms that the protease is indeed an MMP with gelatinolytic activity. Results from that inhibition experiment also excludes the presence of other MMPs such as stromelysins or collagenases that have low specificity for gelatin. The involvement of cysteine capthepsins can also be ruled out because gelatinolytic activity was observed when the gel was incubated with the cysteine protease inhibitor E-64.

Immunohistochemical techniques, which use highly specific primary monoclonal antibodies, are advantageous in that they are able to identify the precise composition and distribution of specific MMP molecules using both FEI-SEM and TEM. These approaches enable the association between localization and function in-situ $[4,40]$.

\section{Conclusion}

The multi-level biochemical and immunohistochemical approaches employed in the present study identified MMP-7 as a constituent of the human dentin matrix. Identification of MMP-7 in human dentin represents a step forward in the identification of MMPs within the dentin substrate. Inhibition of the MMP-7 should be considered due to the fact that it regulates MMP-2 and -9 activity.

\section{Declarations of interest}

None.

\section{Acknowledgments}

The authors wish to thank Mr. Aurelio Valmori for technical assistance, Dr. Fernando Nato and Miss Rosa Curci for laboratory assistance. The study was partially supported with MIUR grants (Italy). 


\section{References}

[1] I. Stamenkovic, Extracellular matrix remodelling: the role of matrix metalloproteinases, J. Pathol. 200 (2003) 448-464, https://doi.org/10.1002/path.1400.

[2] A. Page-McCaw, A.J. Ewald, Z. Werb, Matrix metalloproteinases and the regulation of tissue remodelling, Nat. Rev. Mol. Cell Biol. 8 (2007) 221-233, https://doi.org/ $10.1038 / \mathrm{nrm} 2125$.

[3] H. Palosaari, C. Pennington, M. Larmas, L. Tjäderhane, T. Salo, Expression profile of matrix metalloproteinases (MMPs) and tissue inhibitors of MMPs in mature human odontoblasts and pulp tissue, Eur. J. Oral Sci. 111 (2003) 117-127.

[4] A. Mazzoni, D.H. Pashley, F.R. Tay, P. Gobbi, G. Orsini, A. Ruggeri, M. Carrilho, L. Tjäderhane, R. Di Lenarda, L. Breschi, Immunohistochemical identification of MMP-2 and MMP-9 in human dentin: correlative FEI-SEM/TEM analysis, J. Biomed. Mater. Res. - Part A. 88 (2009) 697-703, https://doi.org/10.1002/jbm.a.31920.

[5] A. Mazzoni, F. Mannello, F.R. Tay, G.A.M. Tonti, S. Papa, G. Mazzotti, R. Di Lenarda, D.H. Pashley, L. Breschi, Zymographic analysis and characterization of MMP-2 and -9 forms in human sound dentin, J. Dent. Res. 86 (2007) 436-440, https://doi.org/10.1177/154405910708600509.

[6] M. Sulkala, T. Tervahartiala, T. Sorsa, M. Larmas, T. Salo, L. Tjäderhane, Matrix metalloproteinase-8 (MMP-8) is the major collagenase in human dentin, Arch. Oral Biol. 52 (2007) 121-127, https://doi.org/10.1016/j.archoralbio.2006.08.009.

[7] Y. Shimada, S. Ichinose, A. Sadr, M.F. Burrow, J. Tagami, Localization of matrix metalloproteinases (MMPs-2, 8, 9 and 20) in normal and carious dentine, Aust. Dent. J. 54 (2009) 347-354, https://doi.org/10.1111/j.1834-7819.2009.01161.x.

[8] A. Mazzoni, V. Papa, F. Nato, M. Carrilho, L. Tjäderhane, A. Ruggeri, P. Gobbi, G. Mazzotti, F.R. Tay, D.H. Pashley, L. Breschi, Immunohistochemical and biochemical assay of MMP-3 in human dentine, J. Dent. 39 (2011) 231-237, https:// doi.org/10.1016/j.jdent.2011.01.001.

[9] L. Tjäderhane, M.A.R. Buzalaf, M. Carrilho, C. Chaussain, Matrix metalloproteinases and other matrix proteinases in relation to cariology: the era of "dentin degradomics,", Caries Res. 49 (2015) 193-208, https://doi.org/10.1159/000363582.

[10] A. Mazzoni, L. Tjäderhane, V. Checchi, R. Di Lenarda, T. Salo, F.R. Tay, D.H. Pashley, L. Breschi, Role of dentin MMPs in caries progression and bond stability, J. Dent. Res. 94 (2015) 241-251, https://doi.org/10.1177/ 0022034514562833.

[11] A. Mazzoni, F.M. Apolonio, V.P.A. Saboia, S. Santi, V. Angeloni, V. Checchi, R. Curci, R. Di Lenarda, F.R. Tay, D.H. Pashley, L. Breschi, Carbodiimide inactivation of MMPs and effect on dentin bonding, J. Dent. Res. 93 (2014) 263-268, https://doi.org/10.1177/0022034513516465.

[12] M.A.R. Buzalaf, S. Charone, L. Tjäderhane, Role of host-derived proteinases in dentine caries and erosion, Caries Res. 49 (2015) 30-37, https://doi.org/10.1159/ 000380885

[13] L. Tjäderhane, H. Larjava, T. Sorsa, V.-J. Uitto, M. Larmas, T. Salo, The activation and function of host matrix metalloproteinases in dentin matrix breakdown in caries lesions, J. Dent. Res. 77 (1998) 1622-1629, https://doi.org/10.1177/ 00220345980770081001.

[14] C.M.P. Vidal, L. Tjäderhane, P.M. Scaffa, I.L. Tersariol, D. Pashley, H.B. Nader, F.D. Nascimento, M.R. Carrilho, Abundance of MMPs and cysteine cathepsins in caries-affected dentin, J. Dent. Res. 93 (2014) 269-274, https://doi.org/10.1177/ 0022034513516979.

[15] A. Mazzoni, P. Scaffa, M. Carrilho, L. Tjäderhane, R. Di Lenarda, A. Polimeni, A. Tezvergil-Mutluay, F.R. Tay, D.H. Pashley, L. Breschi, Effects of etch-and-rinse and self-etch adhesives on dentin MMP-2 and MMP-9, J. Dent. Res. 92 (2013) 82-86, https://doi.org/10.1177/0022034512467034.

[16] F.M. Apolonio, A. Mazzoni, V. Angeloni, P.M.C. Scaffa, S. Santi, V. de P.A. Saboia, F.R. Tay, D.H. Pashley, L. Breschi, Effect of a one-step self-etch adhesive on en dogenous dentin matrix metalloproteinases, Eur. J. Oral Sci. 125 (2017) 168-172, https://doi.org/10.1111/eos.12337.

[17] A. Mazzoni, F. Nascimento, M. Carrilho, I. Tersariol, V. Papa, L. Tjaderhane, R. Di Lenarda, F. Tay, D. Pashley, L. Breschi, MMP activity in the hybrid layer detected with in situ zymography, J. Dent. Res. 91 (2012) 467-472, https://doi.org/10. $1177 / 0022034512439210$

[18] A. Tocchi, W.C. Parks, Functional interactions between matrix metalloproteinases and glycosaminoglycans, FEBS J. 280 (2013) 2332-2341, https://doi.org/10.1111/ febs.12198.

[19] F.Q. Wang, J. So, S. Reierstad, D.A. Fishman, Matrilysin (MMP-7) promotes invasion of ovarian cancer cells by activation of progelatinase, Int. J. Cancer 114 (2005) 19-31, https://doi.org/10.1002/ijc.20697.

[20] K. Imai, Y. Yokohama, I. Nakanishi, E. Ohuchi, Y. Fujii, N. Nakai, Y. Okada, Matrix metalloproteinase 7 (matrilysin) from human rectal carcinoma cells: activation of the precursor, interaction with other matrix metalloproteinases and enzymic properties, J. Biol. Chem. 270 (1995) 6691-6697, https://doi.org/10.1074/jbc 270.12 .6691$.

[21] M. Balbín, A. Fueyo, V. Knäuper, A.M. Pendás, J.M. López, M.G. Jiménez,
G. Murphy, C. López-Otín, Collagenase 2 (MMP-8) expression in murine tissue-remodeling processes. Analysis of its potential role in postpartum involution of the uterus, J. Biol. Chem. 273 (1998) 23959-23968, https://doi.org/10.1074/jbc.273. 37.23959.

[22] R. O'Grady, A. Nethery, N. Hunter, A fluorescent screening assay for collagenase using collagen labeled with 2-Methoxy-2,4-diphenyl-3(2H)-furanone, Anal. Biochem. 140 (1984) 490-494.

[23] J. Perdigão, P. Lambrechts, B. Van Meerbeek, G. Vanherle, A.L.B. Lopes, Field emission SEM comparison of four postfixation drying techniques for human dentin, J. Biomed. Mater. Res. 29 (1995) 1111-1120, https://doi.org/10.1002/jbm. 820290911.

[24] H.-C. Chuang, C.-Y. Su, H.-Y. Huang, C.-C. Huang, C.-Y. Chien, Y.-Y. Du, J.$\mathrm{H}$. Chuang, Active matrix metalloproteinase-7 is associated with invasion in buccal squamous cell carcinoma, Mod. Pathol. 21 (2008) 1444-1450, https://doi.org/10. 1038/modpathol.2008.99.

[25] G. Murphy, M.I. Cockett, R.V. Ward, A.J. Docherty, Matrix metalloproteinase degradation of elastin, type IV collagen and proteoglycan. A quantitative comparison of the activities of $95 \mathrm{kDa}$ and $72 \mathrm{kDa}$ gelatinases, stromelysins- 1 and -2 and punctuated metalloproteinase (PUMP), Biochem. J. 277 (1991) 277-279.

[26] A. Siri, V. Knauper, N. Veirana, F. Caocci, G. Murphy, L. Zardi, Different susceptibility of small and large human tenascin-C isoforms to degradation by matrix metalloproteinases, J. Biol. Chem. 270 (1995) 8650-8654, https://doi.org/10. $1074 /$ jbc. 270.15.8650.

[27] K. Imai, A. Hiramatsu, D. Fukushima, M.D. Pierschbacher, Y. Okada, Degradation of decorin by matrix metalloproteinases: identification of the cleavage sites, kinetic analyses and transforming growth factor-beta1 release, Biochem. J. 322 (1997) 809-814.

[28] R. Agnihotri, H.C. Crawford, H. Haro, L.M. Matrisian, M.C. Havrda, L. Liaw, Osteopontin, a novel substrate for matrix metalloproteinase- 3 (stromelysin-1) and matrix metalloproteinase-7 (matrilysin), J. Biol. Chem. 276 (2001) 28261-28267, https://doi.org/10.1074/jbc.M103608200.

[29] V. Noë, B. Fingleton, K. Jacobs, H.C. Crawford, S. Vermeulen, W. Steelant, E. Bruyneel, L.M. Matrisian, M. Mareel, Release of an invasion promoter E-cadherin fragment by matrilysin and stromelysin-1, J. Cell. Sci. 114 (2001) 111-118.

[30] A. Gearing, S. Thorpe, K. Miller, M. Mangan, P. Varley, T. Dudgeon, G. Ward, C. Turner, R. Thorpe, Selective cleaveage of human IgG by the matrix metalloproteinases matrilysin and stromelysin, Immunol. Lett. 81 (2002) 41-48.

[31] R. Schure, K.D. Costa, R. Rezaei, W. Lee, C. Laschinger, H.C. Tenenbaum, C.A. Mcculloch, Impact of matrix metalloproteinases on inhibition of mineralization by fetuin, J. Periodont. Res. Suppl. 48 (2013) 357-366, https://doi.org/10.1111/ jre.12015.

[32] A. Mazzoni, L. Breschi, M. Carrilho, F.D. Nascimento, G. Orsini, A. Ruggeri, P. Gobbi, L. Manzoli, F.R. Tay, D.H. Pashley, L. Tjäderhane, A review of the nature, role, and function of dentin non-collagenous proteins. Part II: enzymes, serum proteins, and growth factors, Endod. Top. 21 (2009) 19-40, https://doi.org/10. 1111/j.1601-1546.2012.00268.x.

[33] J. Ochieng, P. Warfield, B. Green, Interactions of gelatinases with soluble and immobilized fetuin and asialofetuin, Arch. Biochem. Biophys. 322 (1995) 250-255, https://doi.org/10.1006/ABBI.1995.1459.

[34] C. Lee, E. Bongcam-Rudloff, C. Sollner, W. Jahnen-Dechent, L. Claesson-Welsh, Type 3 cystatins; fetuins, kininogen and histidine-rich glycoprotein, Front. Biosci. 14 (2009) 2911-2922.

[35] S. Ray, P. Lukyanov, J. Ochieng, Members of the cystatin superfamily interact with MMP-9 and protect it from autolytic degradation without affecting its gelatinolytic activities, Biochim. Biophys. Acta - Proteins Proteomics 1652 (2003) 91-102, https://doi.org/10.1016/J.BBAPAP.2003.08.004.

[36] D. Kübler, D. Gosenca, M. Wind, H. Heid, I. Friedberg, W. Jahnen-Dechent, W.D. Lehmann, Proteolytic processing by matrix metalloproteinases and phosphorylation by protein kinase CK2 of fetuin-A, the major globulin of fetal calf serum, Biochimie 89 (2007) 410-418, https://doi.org/10.1016/J.BIOCHI.2006.10. 012.

[37] G. Turco, A. Frassetto, L. Fontanive, A. Mazzoni, M. Cadenaro, R. Di Lenarda, F.R. Tay, D.H. Pashley, L. Breschi, Occlusal loading and cross-linking effects on dentin collagen degradation in physiological conditions, Dent. Mater. 32 (2016) 192-199, https://doi.org/10.1016/j.dental.2015.11.026.

[38] G. Turco, M. Cadenaro, T. Maravić, A. Frassetto, E. Marsich, A. Mazzoni, R. Di Lenarda, F.R. Tay, D.H. Pashley, L. Breschi, Release of ICTP and CTX telopeptides from demineralized dentin matrices: effect of time, mass and surface area, Dent. Mater. 34 (2018) 452-459, https://doi.org/10.1016/j.dental.2017.12.003.

[39] S. Perumal, O. Antipova, J.P.R.O. Orgel, Collagen fibril architecture, domain organization, and triple-helical conformation govern its proteolysis, Proc. Natl. Acad. Sci. 105 (2008) 2824-2829, https://doi.org/10.1073/pnas.0710588105.

[40] M.D. Mckee, A. Nanci, Ultrastructural, cytochamical and immunocytochemical studies on bone and its interfaces, Cells Mater. 3 (1993) 219-243. 